\title{
A BRIEF OVERVIEW OF THE TYPES OF ETFS
}

\section{Elitsa PETROVA}

National Military University, Veliko Tarnovo, Bulgaria

E-mail: elitsasd@abv.bg

\begin{abstract}
Exchange-traded fund is a type of exchange-traded product. ETF is a fund that is traded as a typical financial asset. Just like an index fund, ETF represents a basket of assets that reflect popular stock index. ETF traded just like any other company on the stock exchange. By owning ETF investor receives two important advantages - the diversification of index fund plus the flexibility of trading financial assets. There are different types of ETFs. Mainly divided into index, commodity, bond, currency, exchange-traded trusts and leveraged exchange-traded funds.

The article discusses the basics of exchange-traded fund, does a brief history review on the emergence of exchange-traded funds, and provides information on the basic and specific types of exchange-traded funds.

The used scientific tools include:

- study of scientific literature;

- study the performance of different markets which operate with exchange-traded funds;

- meaningful analysis and summary of theoretical and practical applied information.
\end{abstract}

Keywords: exchange-traded fund, types of ETFs, financial asset

JEL classification: $\mathbf{G}_{12}$

\section{Introduction}

ETFs (Exchange-traded fund) are a type of financial instrument whose unique advantages attract many investors. ETF is a fund that is traded as a typical financial asset. Just like an index fund, ETF represents a basket of assets that reflect popular stock index. ETF traded just like any other company on the stock exchange. Unlike a mutual fund which has a net asset value calculated at the end of each trading day, ETF's price changes throughout the day depending on supply and demand.

\section{Nature and importance of ETFs}

ETFs began its development in 1989 with the S\&P 500 proxy, which is traded on the American Stock Exchange and Philadelphia Exchange. This product, however, had a short life after "Chicago Mercantile Exchange" to stop its sales. 
Similar product began trading on TSX [www.tmx.com] in 1990. Originally shares tracked by index TSE are 35 and later they reached number of 100.

Nathan Most and Steven Bloom designed and developed Standard \& Poor's Depositary Receipts, (NYSE: SPY). Introduced in January 1993 and known as SPDRs or "spiders" the fund became the biggest exchange-traded fund in the world. In May 1995 they created MidCap SPDRs (NYSE: MDY).

Barclays Global Investors, a subsidiary of Barclays Plc [http://group.barclays.com/home], entered in 1996 with World Equity Benchmark Shares, WEBS, subsequently renamed iShares MSCI Index Fund Shares. WEBS are an innovative oriented and provides easy access to foreign markets. While SPDRs are organized as investment trusts, WEBS created the first-ever mutual fund. [Wiandt, J., \& McClatchy, W., 2002]

In 1998 "Dow Diamonds" (NYSE: DIA) are introduced to the market, which follow the famous Dow Jones Industrial. In 1999 influential "cubes" (NASDAQ: QQQQ) began to reproduce the NASDAQ-100 [http://www.nasdaq.com]. iShares of "Barclays Global Investors" started in 2000 and within five years surpassed the assets of any other competitive ETF in the US and Europe. Barclays Global Investors was sold to BlackRock in 2009. Vanguard was released in 2001. [https://investor.vanguard.com/corporate-portal]

ETFs are traditionally index funds; however, in 2008 the Securities and Exchange Commission of the United States allowed the creation of actively managed ETFs. In the 21st century ETFs are multiplied, taking into account the more specific set of classes' assets.

Table no. 1

The Largest ETFs by Assets under Management

\begin{tabular}{|l|l|c|r|}
\hline Symbol & \multicolumn{1}{|c|}{ Name } & AUM & \multicolumn{1}{c|}{ Avg Volume } \\
\hline SPY & SPDR S \& P 500 & $\$ 129,435.8 \mathrm{M}$ & $127,299,508$ \\
\hline GLD & SPDR Gold Trust & $\$ 62,729.3 \mathrm{M}$ & 10.380 .529 \\
\hline VWO & Emerging Markets ETF & $\$ 58,393.8 \mathrm{M}$ & $18,541,262$ \\
\hline EEM & MSCI Emerging Markets Index Fund & $\$ 45,528.7 \mathrm{M}$ & $51,044,004$ \\
\hline EFA & MSCI EAFE Index Fund & $\$ 41,348.2 \mathrm{M}$ & $17,976,365$ \\
\hline IVV & Core S \& P 500 ETF & $\$ 40,637.2 \mathrm{M}$ & $3,892,555$ \\
\hline QQQ & QQQ & $\$ 31,926.6 \mathrm{M}$ & $33,018,621$ \\
\hline VTI & Total Stock Market ETF & $\$ 28,898.5 \mathrm{M}$ & $2,183,142$ \\
\hline LQD & iBoxx \$ Investment Grade Corporate Bond & $\$ 23,688.7 \mathrm{M}$ & $2,143,665$ \\
& Fund & & \\
\hline IWM & The Russell 2000 Index Fund & $\$ 21,471.9 \mathrm{M}$ & $33,831,383$ \\
\hline TIP & Barclays TIPS Bond Fund & $\$ 20,725.2 \mathrm{M}$ & $1,258,152$ \\
\hline
\end{tabular}

Note 1 The term "Assets Under Management - AUM" shows the market value of assets investment company managed on the behalf of investors. Assets under management (AUM) are regarded as measure of success against competition and comprise growth/drop is due to the increase/ loss of capital and new inflow/outflow of money.

Note 2 The term "Average Volume" shows the average number of traded shares.

Source: http://etfdb.com/compare/market-cap 
ETFs can be an attractive investment option because of its low costs and tax efficiency. By owning exchange-traded fund investor receives two important advantages - the diversification of an index fund plus the flexibility of trading financial assets.

Only authorized participants (usually large institutional investors) buy or sell shares of the ETF directly from the fund manager. Individuals also can trade ETF shares, but at the secondary market through retail brokers. Existing ETF portfolios are transparent. Unlike traditional mutual funds, financial institutions purchase and redeem shares of exchange-traded fund directly from it, but only in large blocks, ranging in size from 25,000 to 200,000 shares, called "units". The ability to purchase and redeem shares of ETFs is defined as an arbitration mechanism designed to minimize the potential difference between the market price and net asset value per share of the ETF.

ETFs are characterized by transparency of portfolios and generally have lower costs than other investment products, because most of them are not actively managed. There is flexibility in buying and selling of assets. ETFs can be bought and sold at current market prices at any time of the trading day, unlike mutual funds that can be traded at the end of the trading day. ETFs are tax efficient. Typically generate relatively low capital gains, as they have low turnover of portfolio securities. ETF provide an economical way to rebalance, i.e. portfolio diversification across the index.

\section{Types of ETFs}

Index ETFs are those ETFs that try to follow the stock market indices, such as repeat or complete contents or kept in its portfolio a representative sample of the securities that are in the index. Some indexed ETFs invest $100 \%$ of their assets in proportion to securities underlying the index. Thus investing is called "replication". Other indexed ETFs use "representative sample" of the securities in the index, i.e. invest $80 \%$ to $95 \%$ of its assets in securities of the underlying index and investing the remaining $5 \%$ to $20 \%$ of its assets in other assets, such as futures, options and swap contracts. [http://etfdb.com/compare/market-cap]

Commodity ETFs are investment funds that track the performance of the underlying index of a single asset/commodity. The earliest commodity ETFs (e.g., GLD and SLV, i.e. gold or silver) have traded precious metals (e.g. gold and silver bars). Like them NYSE: PALL has palladium [http://www.nyse.com/about/listed/lcddata.html?ticker=PALL] and NYSE: PPLT platinum [http://www.nyse.com/about/listed/lcddata.html?ticker=PPLT].

Commodity ETFs (Commodity ETFs, ETCs / CETFs) invest in precious metals and futures. They do not invest in securities. The first product, which is marketed by this type of fund, is gold. The first gold-exchange traded fund is Gold Bullion Securities [http://www.etfsecurities.com], which launched on ASX in 2003 and the first silver-exchange traded fund is iShares Silver Trust, which launched on the NYSE in 2006. Till November 2010 SPDR Gold Shares 
[http://www.etfglobalinvestor.net/gold-etf.php] was the second largest ETF by market capitalization.

Exchange-traded funds which invest in bonds are known as Bond ETFs. They develop during economic recessions, when investors withdraw money from the stock market and invest them in bonds for example, treasury bonds or bonds of companies that are considered to be financially stable.

In 2005, Rydex Investments launched its first-ever currency exchange traded fund (Currency ETFs) called the Euro Currency Trust (NYSE:FXE) [http://www.nyse.com/about/listed/lcddata.html?ticker=FXE] in New York. Since then Raydeks launched a series of tools for tracking all major currencies under its own brand CurrencyShares. In 2007 Deutsche Bank launched EONIA Total Return Index ETF in Frankfurt trading the euro, and later in 2008 appeared Sterling Money Market ETF (LSE: XGBP) and US Dollar Money Market ETF (LSE: XUSD) in London [http://www.londonstockexchange.com]. In 2009 ETF Securities [http://www.etfsecurities.com] launched the world's largest FX platform tracking currency called MSFX ${ }^{\mathrm{SM}}$ Index.

Leveraged ETFs (Leveraged exchange-traded funds) are a special type of ETF, which is more sensitive to market movements. [http://www.marketwatch.com] Leverage funds are often used in a situation of a bull market. Leveraged ETF at bull market may attempt to achieve a daily return that is $2 \mathrm{x}$ or $3 \mathrm{x}$ more than a certain index. Leveraged ETFs require the use of financial engineering techniques, including swaps of capital, derivatives and rebalancing the portfolio to achieve the desired return. The most common way to build leveraged ETFs is through contracts for future contracts.

Rebalancing of leveraged ETF could have significant costs when markets are unstable. It is possible to realize the fund trading losses, because it has to buy assets when the index rises and sell assets, when the index drops to maintain certain leverage ratio. So, daily change in the index of $2.5 \%$ would reduce the value of the fund 2 times.

Actively managed ETFs [http://www.sec.gov/rules/concept/ic-25258.htm] (AMETFs) are recently launched worldwide. The first of these occurred in March 2008 in the United States. Actively managed ETFs are fully transparent and publish daily current securities portfolios on their web pages. Actively managed ETFs have grown in recent years and are considered as a significant competitive threat to the actively managed mutual funds.

Exchange-traded trusts ETFs (Exchange-traded grantor trust) consist of static basket of stocks selected from a specific sector. A leading example is the "Holding Company Depositary Receipts" or HOLDRS, which is a product of Merrill Lynch. HOLDRS are either index funds or actively managed funds, where the investor has a direct interest in investing in specific stocks. HOLDRS [http://www.amex.com/holdrs/HrMain.jsp] have some common characteristics with ETFs, including low fees and tax efficiency, but many scientists believe they may be a separate product from ETFs. [Ghosh, R.P., 2005]

ETFs are tax efficient and can be more attractive than mutual funds. In the US mutual fund must distribute the capital gains to its shareholders. This can 
happen when the fund sells securities in order to reallocate their investments or to finance the redemption of shares. These profits are taxed for all shareholders. In contrast, ETFs are not bought by the holders. Instead, holders simply sell their ETF shares on the stock market so that investors generally only realize capital gains when they sell their own shares.

ETFs are traded on the stock exchange and each transaction is subject to brokerage commissions. Typical fees of an online brokerage firm in the United States range from $\$ 10$ to $\$ 20$. [Baker, M.J., 2000]

Perhaps the most important advantage of the ETF is an ability to perform the same types of transactions that can be carried out with all the assets on the stock exchange. For example, investors may make short sales to make purchases on margin, and invest as much money as they want (there is no minimum requirement for investment). Many ETFs have the possibility of using the options (put and call), while mutual funds do not offer this.

According to some critics ETFs can be used to manipulate market prices, including the realization of short sales, which allegedly contributed to the collapse of financial markets in 2008. [Kovak, S., 2007] The founder of the Vanguard Group argues that ETFs are short-term speculation. [Bogle, C.J., 2007] However, he admits that a broadly diversified ETF can be a good investment.

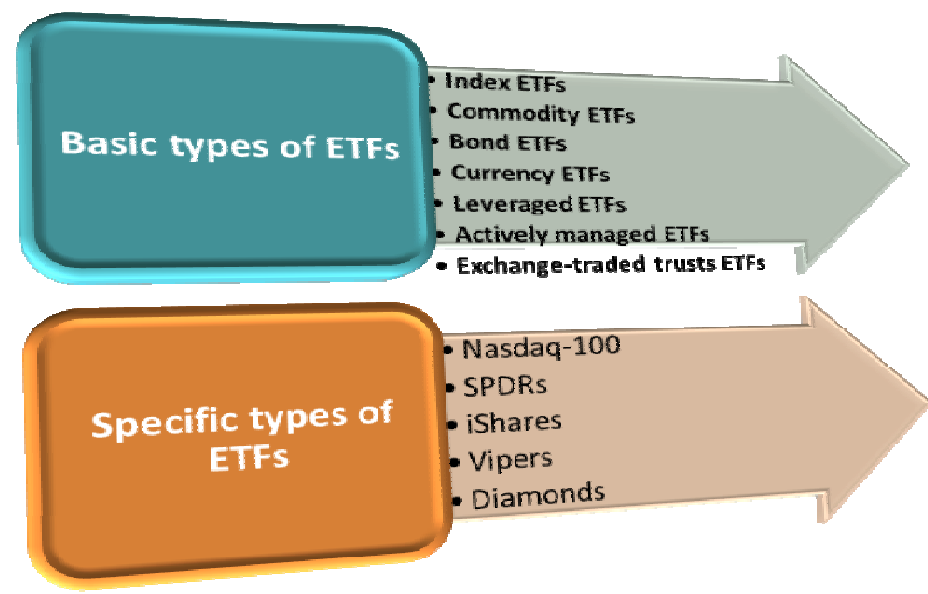

Figure no. 1. ETFs

\section{Specific types of ETFs [http://www.investopedia.com]}

The first exchange-traded fund was the S\&P500 (named "Spiders" because of their stock ticker symbol or SPDR), which began trading on the American Stock Exchange (AMEX) in 1993. Today there are hundreds of ETFs in different sectors of the market. For example, in the health sector operates Vanguard's Health Care Viper (ticker VHT). In the Internet sector works Merrill Lynch's HOLDRS (ticker IIH0). Some of the most popular ETFs have nicknames "Cubes" (QQQQ), vipers (VIPERs) and "Diamonds" (DIAs). Below is a list of some specific types of ETFs. 
- Nasdaq-100 (NASDAQ:QQQQ). This ETF follows the index Nasdaq100 Index, which consists of the 100 largest and most actively traded stocks on the NASDAQ and offers broad exposure to the technology sector. While limiting risk arising from investing in individual stocks, QQQQ is a great way to invest long-term in the technology industry. The offered diversification is a huge advantage when there is instability in the markets. Between 2000 and 2004 QQQQ was the most traded index fund.

- SPDRs. Usually called "Spiders" this investment instrument follows the S\&P 500. SPDRs allow individual investors to hold shares in the index in a cost-effective way to solve problems for the purchase of all 500 companies. Another positive feature of SPDRs is that they divide the different sectors of the S\&P 500 and sell them as separate ETFs. Selected technology sector index, for example, contains over 85 stocks, covering products developed by companies' manufacturers of defence products, telecommunications equipment, microcomputer components and integrated circuits. This ETF is traded under the symbol XLK of AMEX.

- iShares. iShares ETFs is the brand of Barclay (Barclay's Global Investors). In 2009 there were about 350 iShares trading around 300 billion \$. iShares follow many major indexes worldwide. All these ETFs are traded on the major exchanges in the US as normal financial assets.

- Vipers. As iShares are trademarks of Barclay, "Vipers" are Vanguard's ETFs. They are structured as classes of shares of open-ended fund. Vanguard offers dozens of ETFs for many different market areas, including the financial, healthcare, and others.

- Diamonds. "Diamonds Trust Series I" followed Dow Jones Industrial Average. The Fund is structured as an investment trust. Ticker symbol of "Dow Diamonds" is NYSE: DIA. It is traded on the New York Stock Exchange. The combination of diversification, low costs and flexibility makes it one of the most useful innovations and attractive financial engineering instruments.

\section{Conclusion}

Exchange-traded fund is a type of exchange-traded product. By owning ETF investor receives two important advantages - the diversification of index fund plus the flexibility of trading financial assets. There are different types of ETFs. Mainly divided into index, commodity, bond, currency, exchange-traded trusts and leveraged exchange-traded funds. ETFs were traditionally index funds until 2008, when the Securities and Exchange Commission of the United States authorized the creation of an actively managed exchange-traded fund.

\section{References}

- Baker M. J. (2000), Creation Units and the Rise of Exchange-Traded Funds, Investment Adviser, http://www.stradley.com/articles.php?action=view\&id=65

- Bogle, C.J. (2007), Value Strategies, Wall Street Journal, http://online.wsj.com/ article/

44 
- Ghosh, R.P. (2005), HOLDRs Vs. ETF s: What Investors Should Know, Investment Advisor, Summit Business Media, http://www.advisorone.com/2005/08/18 /holdrs-vs-etfs-what-investors-should-know

- Kovak, S. (2007), Just Say No to the Silver ETF, SilverSeek.com, http://news.silverseek.com/SilverSeek/1177698994.php Sons.

- Wiandt, J., \& McClatchy, W. (2002), Exchange Traded Funds, John Wiley and

- http://www.amex.com/holdrs/HrMain.jsp.

- http://etfdb.com/compare/market-cap

- http://www.etfglobalinvestor.net/gold-etf.php

- http://www.etfsecurities.com

- http://group.barclays.com/home

- http://www.investopedia.com

- https://investor.vanguard.com/corporate-portal

- http://www.londonstockexchange.com

- http://www.marketwatch.com/story/profunds-readies-first-leveraged-etfs

- http://www.nasdaq.com

- http://www.nyse.com/about/listed/lcddata.html?ticker=FXE

- http://www.nyse.com/about/listed/lcddata.html?ticker=PALL

- http://www.nyse.com/about/listed/lcddata.html?ticker=PPLT

- http://www.sec.gov/rules/concept/ic-25258.htm

- http://www.tmx.com 
